\title{
PERANCANGAN SIGN SYSTEM MUSEUM NEGERI SUMATERA UTARA
}

\author{
Rinanda Purba \\ Prodi Desain Komunikasi Visual \\ Fakultas Seni dan Desain Universitas Potensi Utama Medan \\ Rinanda.purba.silangit@gmail.com
}

\begin{abstract}
Abstrak
Museum Negeri Sumatera Utara tergolong museum terbesar di Sumatera utara. Karena banyaknya area atau tempat yang terdapat dalam museum tersebut membuat banyaknya kesulitan. Pengunjung masih merasa kebingungan mengenai area-area yang ada di Museum, kurangnya tanda ataupun petunjuk, serta adanya kesalahan petunjuk arah disana. Serta penjagaan yang kurang didalam museum tersebut. Seharusnya museum yang besar dilengkapi dengan fasilitas yang membantu pengunjung, Agar pengunjung merasa nyaman dan terbantu dengan adanya fasilitas tersebut. Museum merupakan tempat yang sangat penting karena berisi benda-benda bersejarah didalamnya. Selain itu kebersihan juga harus sering diperhatikan. Tidak seharusnya sebagai pengunjung mengotori tempat yang bersejarah seperti museum. Untuk itu perlunya fasilitas yang membantu pengunjung. Seperti, Buku panduan area dan tanda area (Sign System) agar pengunjung mudah mengetahui tempat yang sedang dikunjungi. Selain itu fasilitas yang harus dilengkapi adalah petugas atau penjaga museum. Agar museum tetap dengan kondisi yang baik,rapi,dan bersih.
\end{abstract}

Kata kunci: Sign System, Piktogram, Museum Negeri Sumatera Utara

\begin{abstract}
The North Sumatra State Museum is the largest museum in North Sumatra. Because of the many areas or places contained in the museum make a lot of difficulties. Visitors still feel confused about the areas in the Museum, lack of signs or instructions, as well as errors in directions. As well as less guarding in the museum. A large museum should be equipped with facilities that help visitors, so that visitors feel comfortable and helped by the existence of these facilities. The museum is a very important place because it contains historical objects in it. Besides that cleanliness must also be considered. As a visitors, We should not pollute historical places like museums. For this reason, the need for facilities that help visitors. Like, Area guide book and area sign (Sign System) so that visitors easily find out the place that is being visited. In addition, facilities that must be equipped are officers or museum guards. So that the museum remains in good condition, neat, and clean.
\end{abstract}

Keywords: Sign System, Pictograms, North Sumatra State Museum

\section{PENDAHULUAN}

Sumatera Utara adalah salah satu provinsi yang memiliki keragaman, baik dari segi agama atau etnis budaya. Budaya tersebut menjadi identitas bagi Sumatera Utara. Seperti yang kita ketahui budaya yang ada di Sumatera utara, antara lain meliputi Rumah adat, Pakaian tradisional adat, Tarian, Senjata Tradisional, Bahasa Daerah, dan Lagu Daerah.

Untuk itu, pemerintah menyediakan tempat untuk masyarakat agar dapat melihat semua itu dengan mudah di Museum. Museum adalah tempat untuk mengoleksi, menjaga, 
merawat, melestarikan budaya agar tidak terkikis oleh budaya modern. Salah satu museum yang ada di Sumatera Utara adalah Museum Negeri Sumatera Utara.

Berdasarkan koleksi yang ada, Museum Negeri Sumut dikategorikan dalam museum umum. Terdapat ribuan koleksi yang memenuhi isi Museum Negeri Sumatera Utara. Mulai dari, peninggalan Prasejarah, Kebudayaan Sumatera Kuno, Masa Hindu-Buddha, Masa Kerajaan Islam, Koloniallisme Sumatera Utara, Perjuangan Rakyat Sumut, serta peninggalan Gubernur terdahulu dan Pahlawan Sumatera Utara.

Museum Negeri Sumatera Utara tergolong museum terbesar di Sumatera utara. Karena banyaknya area atau tempat yang terdapat dalam museum tersebut membuat banyaknya kesulitan. Pengunjung masih merasa kebingungan mengenai area-area yang ada di Museum, kurangnya tanda ataupun petunjuk, serta adanya kesalahan petunjuk arah disana. Serta penjagaan yang kurang didalam museum tersebut.

Seharusnya museum yang besar dilengkapi dengan fasilitas yang membantu pengunjung. Dengan demikian pengunjung merasa nyaman dan terbantu dengan adanya fasilitas tersebut. Museum merupakan tempat yang sangat penting karena berisi benda-benda bersejarah didalamnya. Selain itu kebersihan juga harus sering diperhatikan. Tidak seharusnya sebagai pengunjung mengotori tempat yang bersejarah seperti museum. Untuk itu perlunya fasilitas yang membantu pengunjung. Seperti, Buku panduan area dan tanda area (Sign System) agar pengunjung mudah mengetahui tempat yang sedang dikunjungi. Selain itu fasilitas yang harus dilengkapi adalah petugas atau penjaga museum. Agar museum tetap dengan kondisi yang baik,rapi,dan bersih.

\section{STUDI LITERATUR}

\section{II.1. Piktogram}

Tanda sering dijumpai dalam kehidupan sehari-hari. Pada saatmenggunakan telepon seluler, sering dijumpai tanda pada screen atau keypad. Tanda tersebut mewakili bentuk gagang telepon, amplop, nada suara, kunci, dan bentuk lain yang menunjukkan beberapa fungsi tombol telepon selular.

Tanda juga sering dijumpai di tempat umum seperti terminal, bandara, stasiun, dan pusat perbelanjaan. Begitu juga halnya ketika hendak ke toilet, terdapat tanda yang menunjukkan bilik khusus pria atau wanita. Hal-hal tersebut lebih dikenal sebagai simbol, yang merupakan penerapan dari piktogram atau piktograf.

Piktogram adalah bentuk simbol grafis (ideogram) yang memiliki konsep, ide dan menyampaikannya melalui kesamaan bentuk dan karakter fisik suatu objek. Sebagai simbol yang merepresentasikan sesuatu secara sederhana, piktogram sering digunakan oleh beberapa kebudayaan kontemporer. Piktogram juga dapat menjadi bahasa yang mengkomunikasikan sebuah informasi secara efektif kepada target audience yang mempunyai bahasa dan budaya yang berbeda. Hal tersebut menjadi alas an bagi rambu di jalan raya dan objek bergambar lainnya ditampilkan secara global dan mempunyai standar tertentu agar mudah dikenali oleh setiap orang.

Sebagai symbol yang bersifat universal, piktogram mempersuasi kita untuk berpikir bagaimana berkomunikasi yang mudah dimengerti oleh setiap orang. Terlepas dari mana asal Negara dan bahasa yang mereka gunakan (Prasetya DH). 


\section{II.2. Sign System}

Sign adalah bentuk komunikasi yang berbentuk verbal dan atau visual. Eksistensi sebuah tanda menjadi sebuah kepentingan bagi masyarakat karena dapat menyampaikan informasi. Menurut Piliang (dalam Sobur, 2003), dalam kata pengantarnya pada buku semiotika komunikasi visual. Tinarbuko (2009) menyatakan bahwa tanda bukan ilmu yang memiliki sifat pasti, melainkan suatu hal yang dibentuk oleh pengetahuan yang lebih terbuka. Yang terpenting dalam sistem tanda adalah fungsinya sebagai penyampai pesan dari pengirim kepada penerima, yang dipengaruhi oleh kode dan media tertentu.

Tanda adalah Segala hal yang dapat diamati dan dibuat teramati menurut Zoest (dalam Tinarbuko 2009, h.12). Sementara menurut Saussure, tanda merupakan kesatuan dari dua bidang yang tidak dapat dipisahkan, yaitu sistem dimana sebuah tanda memiliki dua hal yang ditangkap oleh indra, yaitu penanda dan petanda.

Penanda dijelaskan sebagai tingkatan yang berwujud fisik seperti objek, gambar, warna, huruf. Sementara petanda lebih cenderung mengungkapkan isi atau gagasan dari penanda. Kesimpulannya, hubungan antara keduanyalah yang melahirkan makna (Tinarbuko, 2009: h.91).

Tanda memiliki hubungan yang erat dengan ikon, indeks, dan simbol. Ikon adalah bentuk yang menyerupai bentuk yang diwakilinya, yang memiliki ciri yang sama dengan bentuk aslinya. Indeks adalah sesuatu yang berhubungan sebab dan akibatdari yangdiwakilinya. Sementara simbol adalah yang lahir dari peraturan atau kesepakatan bersama. Menurut Piliang (1998, h.17), kode adalah kombinasi tanda yang disepakati bersama dalam menyampaikan pesan kepada penerima pesan (tinarbuko: 2009, h.17).

Sign system merupakan rangkaian representasi visual yang bertujuan sebagai media bagi manusia dalam berinteraksi dalam ruang publik (Tinarbuko: 2012, h.12). Terdapat 4 (empat) bagian dari sign system antara lain:

\section{a. Traffic Sign}

Merupakan sign system yang berada di jalan yang memiliki fungsi untuk menyampaikan informasi kepada pengguna jalan dalam bentuk penunjuk arah, peringatan, dan larangan.

\section{b. Commercial Sign}

Merupakan sign system yang bersifat komersil.

c. Wayfinding Sign

Merupakan sign system yang menjadi penunjuk jalan.

\section{d. Safety Sign}

Meupakan sign system yang menginformasikan pesan yang bersifat peringatan.

\section{II.3. Tipografi}

Menurut Roy Brewer (1971), tipografi dapat diartikan sangat luas yang mencakup susunan dan bentuk halaman, barang cetak. Tipografi juga diartikan sebagai pemilihan, penataan dan hal-hal yang berhubungan dengan typeset, tidak termasuk ilustrasi dan unsurunsur lain selain susunan huruf pada media cetak.

\section{II.4. Teori Warna}

Menurut Dameria (2007:10), warna adalah fenomena yang muncul karena adanya tiga unsur yaitu cahaya, objek, dan observer. Di ruang gelap dimana tidak ada cahaya, maka warna tidak akan dikenali. Demikian halnya apabila menutup mata, maka tidak damat 
melihat warna. Serta apabila tidak ada suatu objek yang dilihat, maka tidak dapat juga dikenali warna tersebut.

Pemilihan warna merupakan salah satu hal yang sangat penting karena audience akan merasakan kesan yang timbul dari warna tersebut sehingga pemdalaman dan pemahaman akan sebuah karya desain dapat lebih mudah. Mata audience akan merespon setiap pilihan warna yang tampil karena warna merupakan bagian awal yang dapat dirasa. Rasa tersebut mampu membawa dan memberikan sugesti kepada target audience. Untuk itu pemilihan warna juga harus disesuaikan dengan target audience yang dituju.

Menurut Pujiriyanto (2005:43), efek dari warna menurut komposisinya ditentukan oleh situasi. Warna selalu dilihat memiliki hubungan dengan lingkungannya. Jika warna dikeluarkan dari lingkarannya, maka warna akan memiliki kekuatan sendiri.

\section{II.5. Museum Negeri Sumatera Utara}

Menurut data dari www.pemkomedan.go.id, Museum Negeri Propinsi Sumut diresmikan pada 19 April 1982. Presiden pertama RI, Ir. Soekarno melakukan peletakan koleksi pertama tahun 1954 berupa makara. Sehingga museum Sumut disebut juga dengan nama Gedung Arca. Posisinya berada pada tempat strategis yaitu dekat dari Bandara Polonia, dan dapat ditempuh dengan jarak sekitar $3 \mathrm{~km}$, dan berjarak $25 \mathrm{~km}$ dari pelabuhan Belawan. Museum Museum ini berada di Jl. H.M. Joni No. 15, Medan.

Dengan bangunan yang memiliki luas 10.468 meter persegi, museum ini dibagi menjadi dua bangunan induk yang memiliki fungsi masing-masing. Ruang-ruang yang ada, dibagi menjadi ruang pameran tetap, ruang pameran temporer, ruang audiovisual, ruang Kepala, Ruang Tata Usaha, ruang seksi bimbingan, perpustakaan, ruang mikro film, ruang komputer, dan gudang. Arsitektur bangunan Museum Sumut dirancang dengan konsep bangunan tradisi Sumut. Hal ini dapat dilihat dari beberapa bagian pada bangunan yang berhiaskan ornament dari etnis melayu, Batak, dan Nias.

Dilihat dari koleksi yang dimiliki oleh Museum Sumut, makan museum ini dikelompokkan sebagai museum umum. Koleksi yang terdapat dalam museum sebagian besar adalah benda peninggalan budaya Sumut.

\section{PEMBAHASAN}

\section{III.1. Sajian Data dan Analisis}

\section{a. Data Visual}

Tabel 1. Data Visual

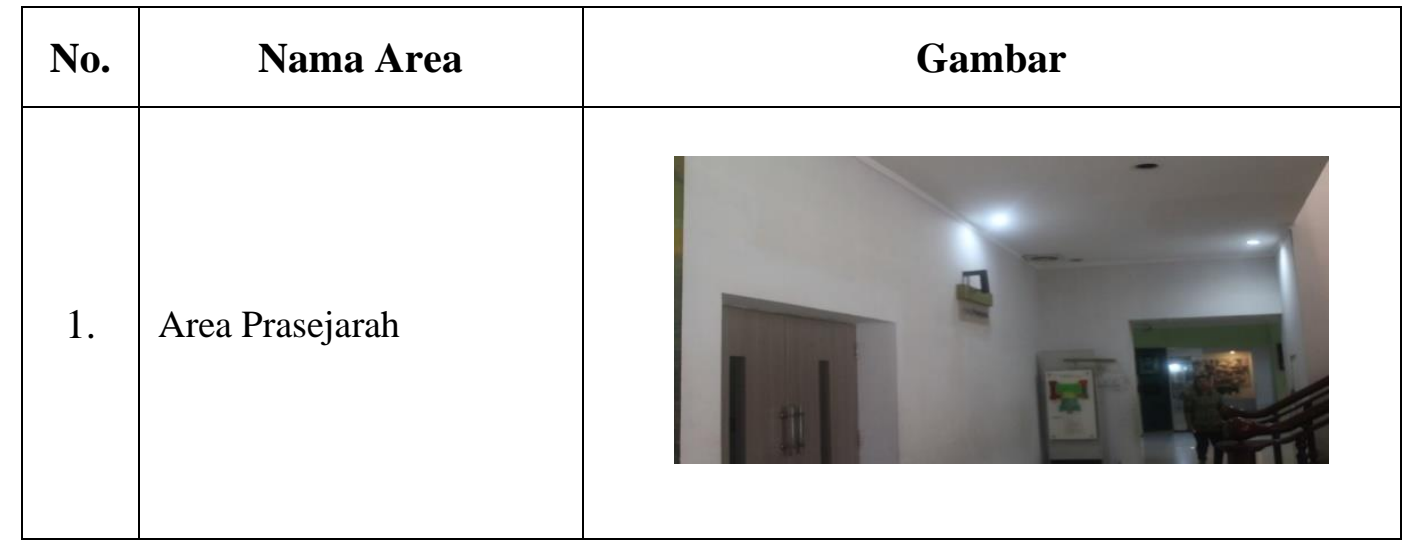




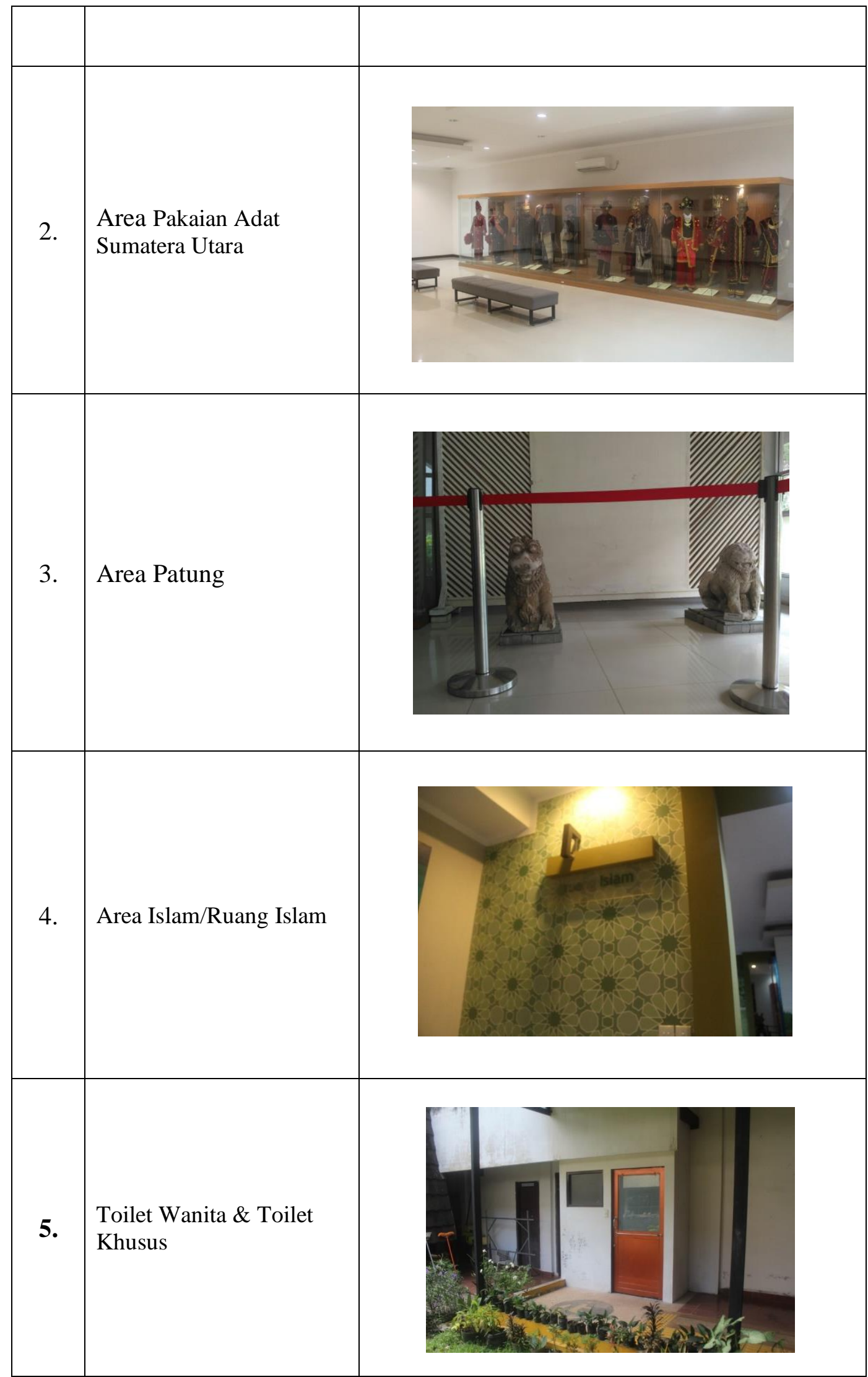




\section{b. Data Verbal}

Menurut hasil wawancara yang telah didapat,dapat disimpulkan bahwa dari segi kebersihan telah baik, tetapi perlu ada penambahan tanda agar pengunjung dapat merasa terbantu. Jika pengunjung merasa terbantu, maka akan berdampak baik bagi museum itu sendiri.

\section{c. Brainstorming}

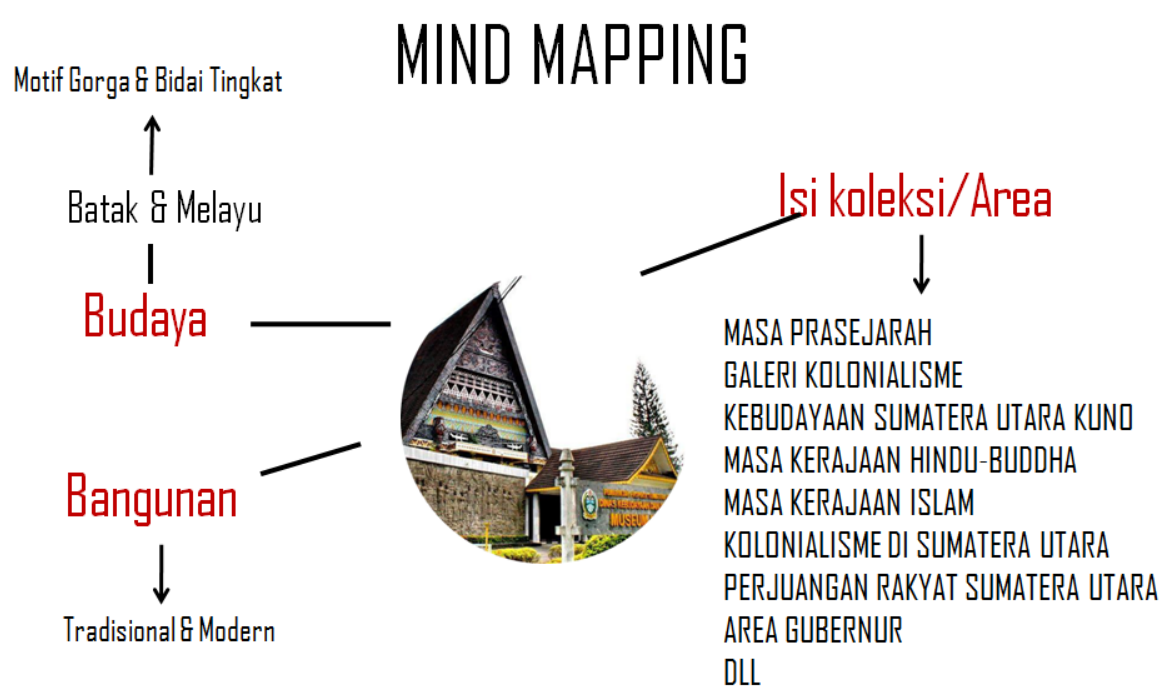

Gambar 1. Analisis data menggunakan Mind Mapping

\section{III.2. Penjaringan Ide dan Konsep}

Konsep Piktogram sendiri diambil dari budaya yang ada di Sumatera Utara, yaitu budaya Batak dan Melayu Dimana dua 2 suku ini sangat mewakili apa yang ada di Sumatera Utara. dari 2 suku ini, Penulis mengambil ornamen yang ada di dalamnya, yaitu Ornamen Gorga dari Batak dan Ornamen Bidai Tingkat yang ada dalam melayu. Sedangkan konsep warna yang digunakan adalah warna yang identik dengan 2 suku tersebut, seperti warna merah, putih,dan hitam yang identik dengan suku Batak dan juga warna kuning dan hijau yang identik dengan suku melayu.

\section{a. Ornamen}
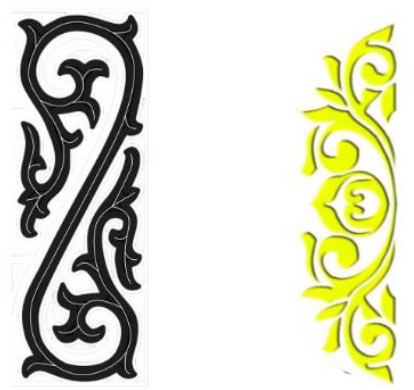

Gambar 2. Ornamen Gorga Dan Bidai Tingkat 


\section{b. Warna}

\section{BATAK}

Merah sebagai perlambang kekuatan (hagogoon), dan keberanian.

Putih sebagai perlanbang suci, habonaron, jujur, dan tulus.

Hitam sebagai perlambang kerahasiaan (hahomion), kewibawaan dan kepemimpinan.

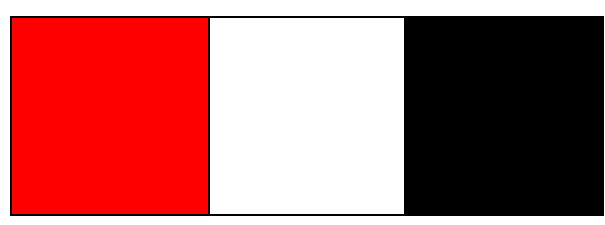

\#FF0000 \#FFFFFF \#000000

\section{MELAYU}

Kuning menjadi lambang kekuasaan kerajaan atau kaum bangsawan.

Hijau melambangkan kesuburan dan tunas baru.

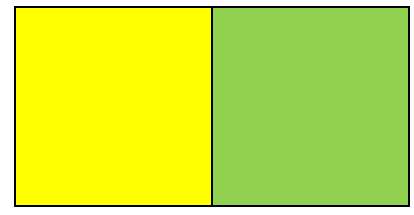

\section{\#FFFF00 \#00FF00}

\section{III.3. Proses Perancangan}

a. Sketsa Alternatif Desain

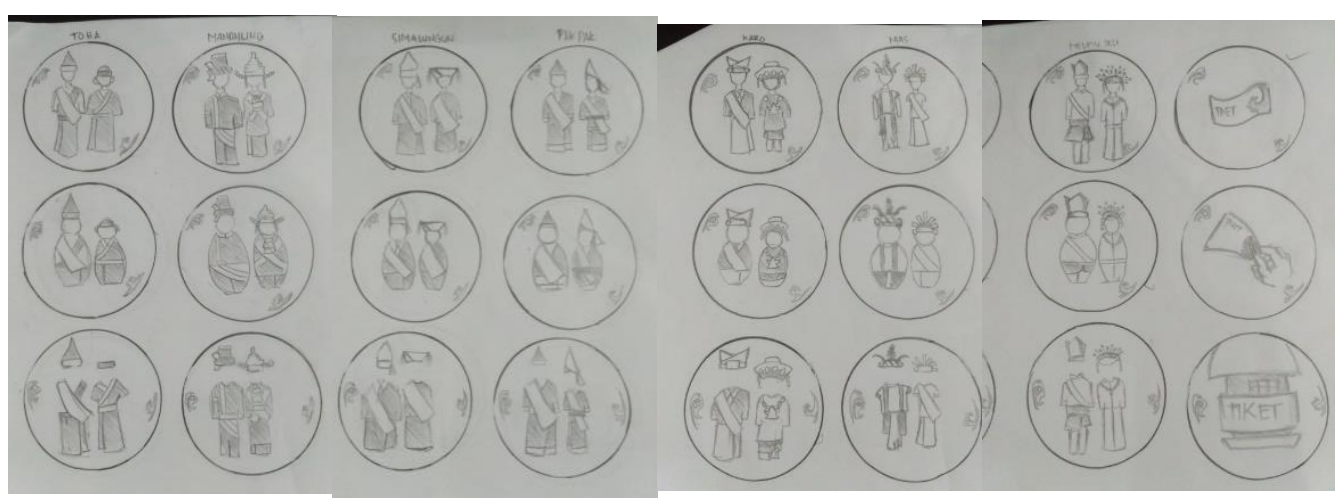

Gambar 3. Sketsa Alternatif Piktogram Batak Toba, Mandailing, Simalungun, Pak Pak, Karo, Nias, Melayu Deli, dan Tiket Masuk 


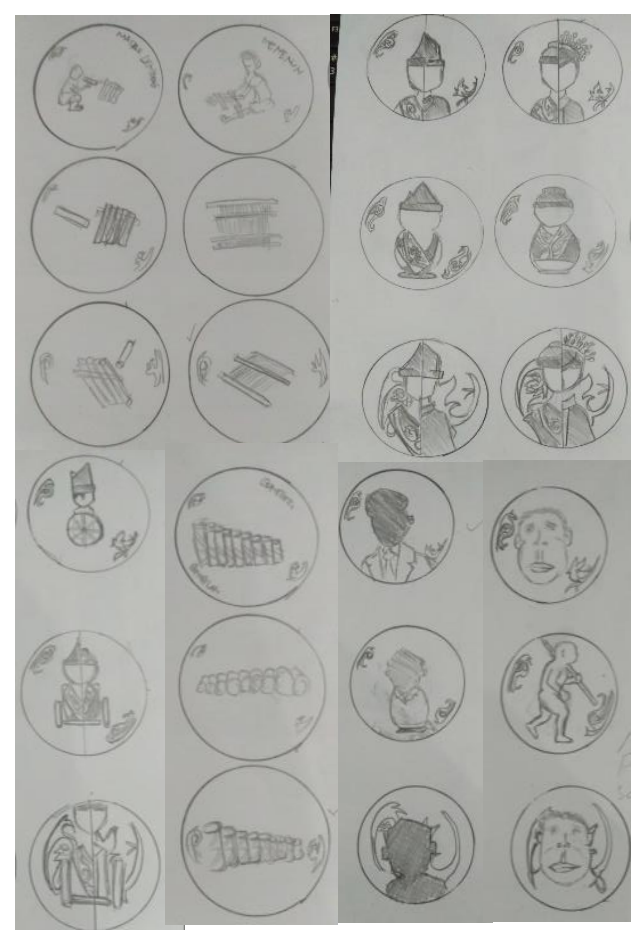

Gambar 4. Sketsa Alternatif

Piktogram Lemang, Menenun

Toilet Pria, Toilet Wanita, Toilet

Khusus, Gondang Sembilan,

Gubernur \& Masa Prasejarah

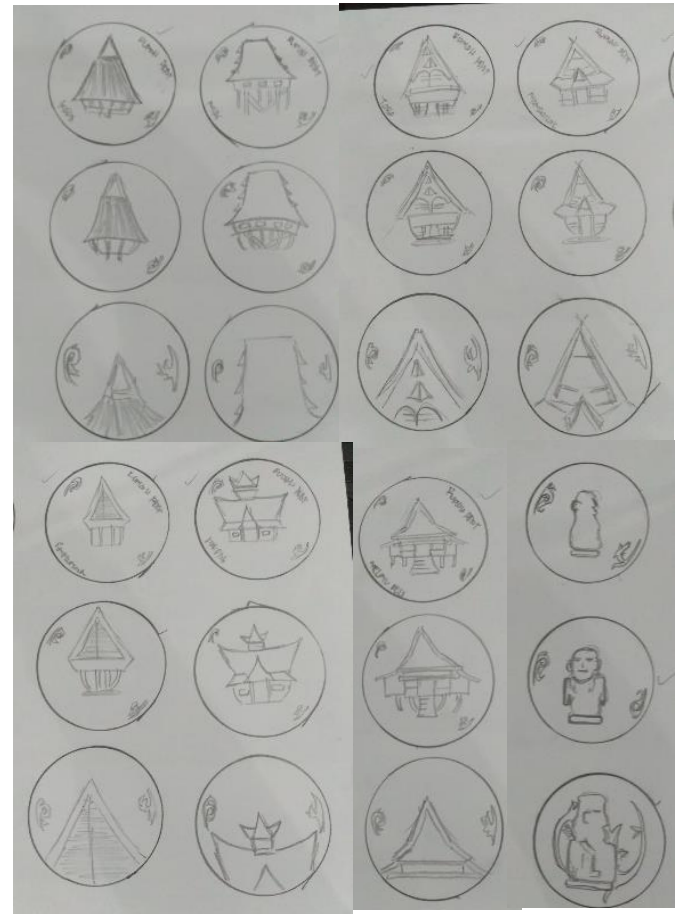

Gambar 5. Sketsa Alternatif

Piktogram Rumah adat Karo,

Nias, Toba, Mandailing,

Simalungun, Pakpak, Melayu, dan

Patung

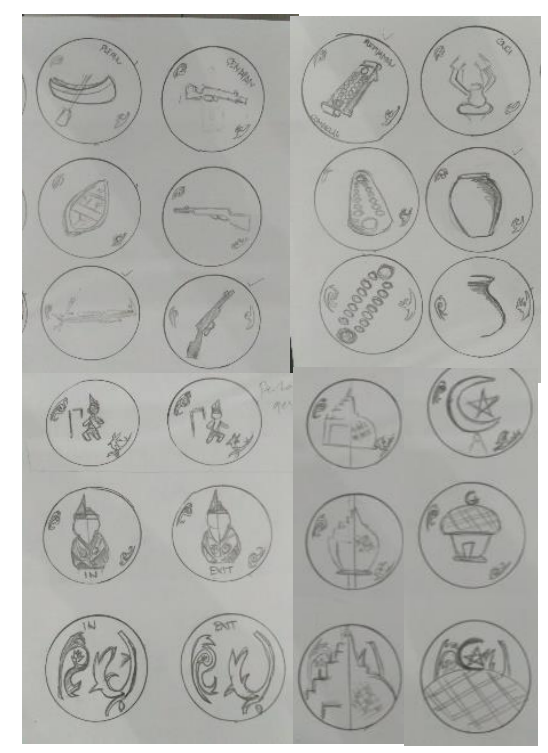

Gambar 6. Sketsa Alternatif Piktogram Rumah adat Karo, Nias, Toba, Mandailing, Simalungun, Pakpak, Melayu, dan Patung 


\section{b. Digital Desain}
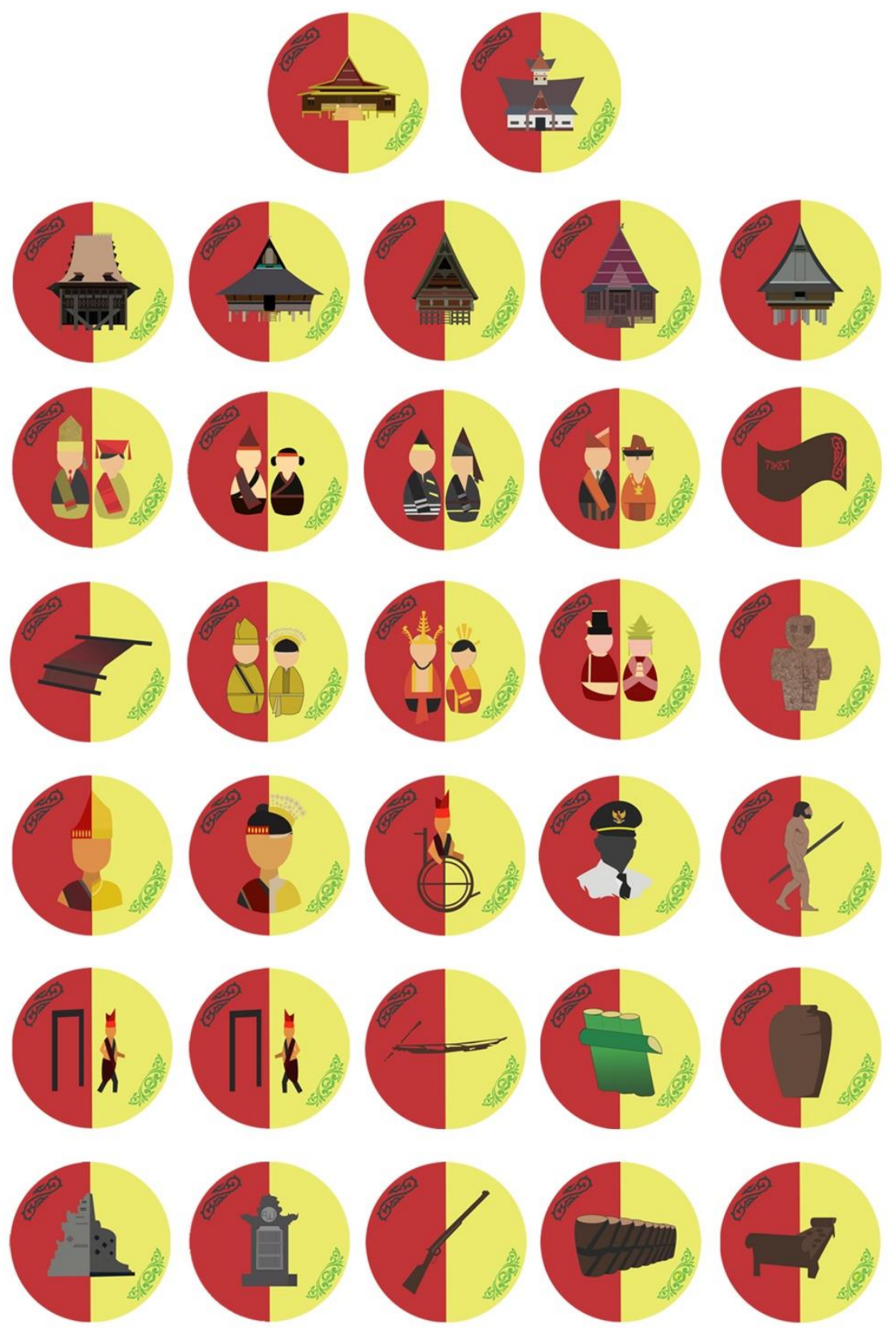

\section{Gambar 7. Digital Desain Piktogram Museum Negeri Sumatera Utara}

\section{KESIMPULAN}

Dari pemaparan di atas, perancangan sign system Museum Negeri Sumatera Utara, peneliti menyimpulkan sebagai berikut:

1. Museum Negeri Sumatera Utara berfungsi sebagai tempat untuk mengumpulkan, merawat, dan melestarikan sejarah serta budaya yang ada di Sumatera Utara. 
2. Kebutuhan terhadap sign system di Museum Negeri Sumatera Utara semakin berkembang terutama dalam hal wayfinding.

3. Selain sebagai petunjuk arah dan untuk penamaan objek, sign system di Museum Negeri Sumatera Utara juga berfungsi sebagai penyampai informasi singkat berupa aturan-aturan yang berlaku di area Museum.

4. Tata letak pemasangan sign system yang baik dan tepat dapat memberikan kejelasan dan kecepatan akses informasi sehingga dapat mempermudah pengunjung dalam mengidentifikasi area atau objek tertentu yang dituju.

5. Penyajian informasi tanda (sign system) dalam bentuk visual yang disajikan menggunakan piktogram dapat sangat membantu Pengunjung. Pengunjung yang terbantu dapat merasa nyaman sehingga memberi nilai lebih terhadap Museum Negeri Sumatera Utara. Selain itu, Piktogram dalam museum diharapkan berguna bagi pihak pengelola.

6. Karya Sign System yang berkonsep budaya batak dan melayu ini merupakan upaya dalam pelestarian budaya local sekaligus mengangkat dan mempopulerkan gaya tradisi pada model desain. Hal tersebut diharapkan mampu mengajak para desainer yang ada di Indonesia, Khususnya di Sumatera Utara agar turut berkarya dengan menggunakan local genius sebagai basic idea.

\section{DAFTAR PUSTAKA}

\section{Buku:}

[1] Dameria, Anne. 2007. Color Basic. Jakarta : Penerbit Link \& Match Graphic.

[2] Kusrianto, Adi.2010.Pengantar Tipografi.Jakarta.PT:PT.Elex Media Komputerindo

[3] Piliang, Yasraf Amir. 1998. Sebuah Dunia yang Dilipat: Realitas Kebudayaan Menjelang Milenium Ketiga dan Matinya Postmodernisme. Bandung: Penerbit Mizan.

[4] Pujiriyanto. 2005. Desain Grafis Komputer. Yogyakarta: Andi.

[5] Sihombing, Danton.2001.TIPOGRAFI dalam seni desain.Jakarta:PT Gramedia Pustaka Utama

[6] Sobur, Alex. 2009. Semiotika Komunikasi. Bandung: Rosda.

[7] Swasty, Wirania.2010.A-Z Warna Interior Rumah Tinggal.Bandung:Griya Kreasi

[8] Tinarbuko, Sumbo. 2009. Semiotika Komunikasi Visual, edisi revisi, Yogyakarta, Jalasutra.

[9] Tinarbuko, Sumbo. 2012. Semiotika Komunikasi Visual. Yogyakarta: Jalasutra.

\section{Sumber Online/Internet:}

[10] Modul Ajar Prasetya DH: https://issuu.com/yonkironic/docs/typography_-_2

[11] http://www.pemkomedan.go.id/artikel-14882-museum-sumatera-utara.html 